\title{
PENGUATAN USAHA DENGAN MENGGUNAKAN SISTEM APLIKASI BY DATA PADA USAHA MINUMAN KEKINIAN DI KOTA TANGERANG SELATAN
}

\author{
Rahmayanti Tumanggor'1), Wiyanto' ${ }^{2)}$, Derizka Inva Jaswita ${ }^{3)}$ \\ ${ }^{1,2,3}$ Program Studi Manajemen, Fakultas Ekonomi, Universitas Pamulang
}

\begin{abstract}
Abstrak
Salah satu yang menjadi incaran dan daya tarik para pelaku usaha UMKM adalah bidang usaha minuman kekinian; sebagai salah satu minuman kegemaran kaum milenial yang sangat menyukai hal-hal yang bersifat praktis, kreatif, dan inovatif. Seiring dengan semakin majunya teknologi dan perkembangan aplikasi IT, juga dimanfaatkan sebagai sarana pemasaran dan promosi bidang usaha Perkembangan dunia usaha minuman kekinian ini menggeliat bukan hanya di kota-kota besar, namun juga menjangkau hingga di tingkat Kota/Kabupaten, bahkan sampai di wilayah Kota Tangerang Selatan. Fenomena menarik yang dapat dijadikan contoh inovasi produk atau jasa adalah para pelaku usaha UKM terutama usaha di bidang minuman. Begitu maraknya bermunculan usaha di bidang ini, menunjukkan semakin baiknya iklim ekonomi mendukung tumbuh kembangnya UKM. Kenyataan inilah yang menarik perhatian kami sebagai pelaksana Pengabdian kepada Masyarakat dari Universitas Pamulang untuk mengetahui seberapa besar pengaruh dan manfaat penggunaan dan penerapan sistem aplikasi by data terhadap peningkatan penjualan minuman kekinian dalam mengembangkan usahanya sehingga tercapai penjualan yang cukup signifikan dan memberi keuntungan secara ekonomis. Tujuan diadakannya PKM ini adalah untuk mengatasi permasalahan dalam mendapatkan ilmu pengetahuan secara teori dan praktek terkait dengan Inovasi Usaha berbasis sistem aplikasi. maka kegiatan Zoom Meeting ini dikemas dengan metode sharing session atau Forum Group Discussion. Hasil dari kegiatan ini diharapkan agar para peserta mendapatkan bekal pengetahuan (knowledge/kognitif) dan keterampilan (digital skill); yang dapat diterapkan dalam mewujudkan kegiatan berwirausaha. Apalagi didukung dengan penggunaan sistem aplikasi "by data" dalam menunjang pengontrolan penjualan yang berdampak kepada peningkatan penjualan dan kemudahan dalam pelayanan kepada konsumen.
\end{abstract}

Kata Kunci : Produk, Profit, Inovasi, Sistem Aplikasi by data, UKM minuman kekinian

\begin{abstract}
One of the targets and attractiveness of UMKM entrepreneurs is the contemporary beverage business; as one of the favorite drinks of millennial who really like things that are practical, creative, and innovative. Along with the advancement of technology and the development of IT applications, it is also used as a means of marketing and promotion of the business sector. The development of the beverage business today is not only in big cities, but also reaches up to the City / Regency level, even in the South Tangerang City area. An interesting phenomenon that can be used as an example of product or service innovation is UKM business actors, especially those in the beverage sector. So many businesses have sprung up in this field, indicating a better economic climate that supports the growth and development of UKM. This fact is what attracts our attention as implementers of Community Service from Pamulang University to find out how much influence and benefits of using and implementing the application by data system on increasing sales of
\end{abstract}


contemporary drinks in developing its business so that significant sales and economic benefits are achieved. The purpose of holding this PKM is to overcome problems in gaining knowledge in theory and practice related to application systembased Business Innovation. Then the Zoom Meeting activity is packaged using the sharing session method or Forum Group Discussion. It is hoped that the results of this activity will provide participants with knowledge (knowledge / cognitive) and skills (digital skills); which can be applied in realizing entrepreneurial activities. Moreover, it is supported by the use of an application system "by data" to support sales control which has an impact on increasing sales and ease of service to consumers.

Keywords: Product, Profit, Innovation, Application System by data, contemporary beverage UKM

Correspondence author: Rahmayanti Tumanggor,dosen02223@unpam.ac.id, South Tangerang, Indonesia

\section{PENDAHULUAN}

Pengembangan usaha dengan teknik Inovasi dianggap akan lebih menjanjikan dan memberikan dampak yang positif bagi pelaku usaha dalam meningkatkan penjualan produk. Hal ini yang membuat munculnya ide untuk bagaimana bisa melakukan pengawasan penjualan langsung oleh pemilik dengan menggunakan teknologi berbasis IT. Aplikasi ini dinamakan "sistem by data".

Keuntungan yang didapat dengan menggunakan sistem ini adalah

1. Pengontrolan penjualan dapat dilaukan secara langsung melalui aplikasi

2. Keuntungan secara ekonomis, mendapatkan promosi gratis melalui sosial media Instagram, Face Book, Go Food, dan Grab Food.

3. Lebih praktis, efisien, waktu

4. Memudahkan karyawan mengingat pesanan sesuai urutan pesanan Terdapat juga resiko menggunakan sistem ini, ketika konsumen membatalkan pesanan, tidak dapat diralat karena sudah masuk ke dalam sistem, dan tidak bisa diubah pesanannya.

Menarik perhatian kami sebagai pelaksana Pengabdian kepada Masyarakat dari Universitas Pamulang untuk mengetahui seberapa besar pengaruh dan manfaat penggunaan dan penerapan sistem aplikasi by data terhadap peningkatan penjualan minuman kekinian. dalam mengembangkan usahanya sehingga tercapai penjualan yang cukup signifikan dan memberi keuntungan secara ekonomis.

Dalam konteks Universitas Pamulang, sebagaimana yang diarahkan oleh Pimpinan agar Mahasiswa tidak hanya menerima dan mendapatkan ilmu berupa Teori "Kewirausahaan", namun juga dapat menberapkan dan mengembamgkannya dalam wujud usaha apakah memproduksi produk baru atau mengembangkan usaha yang sudah ada, disebut dengan Inovasi Usaha. 


\section{METODE PELAKSANAAN}

Metode yang digunakan dalam Pengabdian Kepada masyarakat ini adalah Ceramah dan Tanya Jawab terfokus melalui Zoom Meeting dan Mentorship.

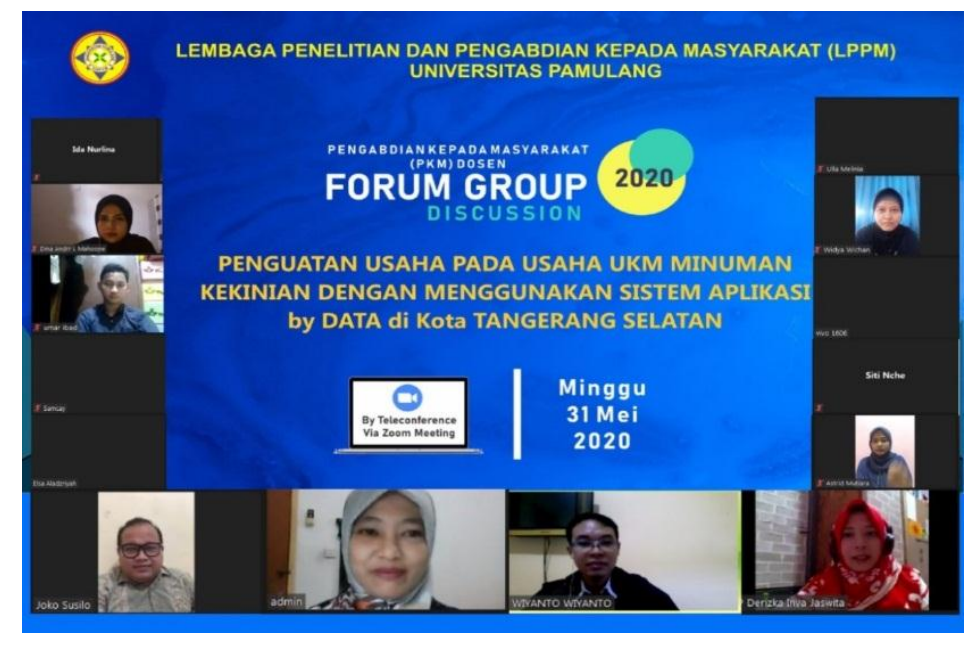

Gambar 1 Zoom Meeting

Pelaksanaan Meeting via Zoom berlangsung pada hari Minggu, 31 Mei 2020 dengan menampilkan 3 (tiga) materi :

Materi 1: Wawasan dan penguasaan 3 digital skill di Era Digital

Materi 2: Penerapan Aplikasi "by data" dalam Inovasi Produk

Materi 3: Meneropong Masa Depan UKM Minuman Kekinian (Hasil Analisa SWOT)

Kegiatan setelah Meeting Zoom adalah Mentoring, dilakukan dalam rangka memberikan pendampingan kepada para peserta Workshop. Tim Pengabdian kepada Masyarakat mendampingi peserta selama kegiatan Workshop berlangsung sampai setelah selesai kegiatan Workshop.

\section{HASIL DAN PEMBAHASAN}

Pelaksanaan kegiatan Pengabdian kepada Masyarakat yakni Workshop dengan tema "Penguatan Usaha dengan Menggunakan Sistem Aplikasi By Data pada Usaha UKM Minuman Kekinian di Kota Tangerang Selatan", menghasilkan pada ranah pengetahuan (knowledge/kognitif) dan keterampilan (digital skill); para peserta Workshop tidak hanya menerima dan mendapatkan ilmu berupa Teori "Kewirausahaan", namun juga dapat menerapkan dan mengembangkannya dalam wujud usaha apakah memproduksi produk baru atau mengembangkan usaha yang sudah ada, disebut dengan Inovasi Usaha; dalam hal ini lebih spesifiknya adalah pengetahuan mengenai sistem aplikasi "by data", yang dapat diaplikasikan dalam bidang usaha yang digeluti. Dengan harapan setelah mengikuti kegiatan workshop ini dapat memicu motivasi para peserta dalam berwirausaha.

Mendalami bagaimana sistem aplikasi "by data" dapat membantu para pelaku usaha minuman kekinian dalam mengembangkan usahanya sehingga tercapai peningkatan penjualan yang cukup signifikan dan memberi keuntungan secara ekonomis. 
Mengikuti pengembangan mulai dari merk (brand), varian rasa, pengemasan, dan pemasaran; produk minuman akan mampu bersaing dengan kompetitor minuman sejenis. Apalagi didukung dengan penggunaan sistem aplikasi "by data" dalam menunjang pengontrolan penjualan yang berdampak kepada peningkatan penjualan dan kemudahan dalam pelayanan kepada konsumen.

Berdasarkan persoalan di atas, maka langkah sederhana yang dapat dilakukan adalah memberikan penguatan kepada UKM minuman kekinian berupa:

1. Memberikan pemahaman tentang 3 digital skill ditengah mewabahnya Covid-19.

2. Melakukan sharing session antara pelaku usaha dengan konsumen dan stake holder dengan keterbukaan hati dan pikiran untuk menciptakan Win-Win.

3. Melakukan SWOT analis secara bersama untuk menentukan langkah strategis bagi usaha UKM minuman kekinian agar tetap eksis di semua kondisi atau keadaan.

Luaran yang dihasilkan dari masing-masing solusi di atas, berupa:

1. Terbangunnya pemahaman tentang 3 digital skill yang harus dikuasai ditengah wabah Covid-19.

2. Terbukanya hati dan pikiran antara pelaku usaha, konsumen dan mitra untuk menciptakan Win-Win dengan value yang berharga dan bermanfaat bagi semua.

3. Dihasilkanya SWOT analisis usaha UKM minuman kekinian dan langkah strategis dalam bentuk Matrix SWOT.

4. Selain ketiga hal di atas, setelah kegiatan ini dilaksanakan dapat terpublikasinya kegiatan pengabdian ini secara online baik berupa berita maupun jurnal.

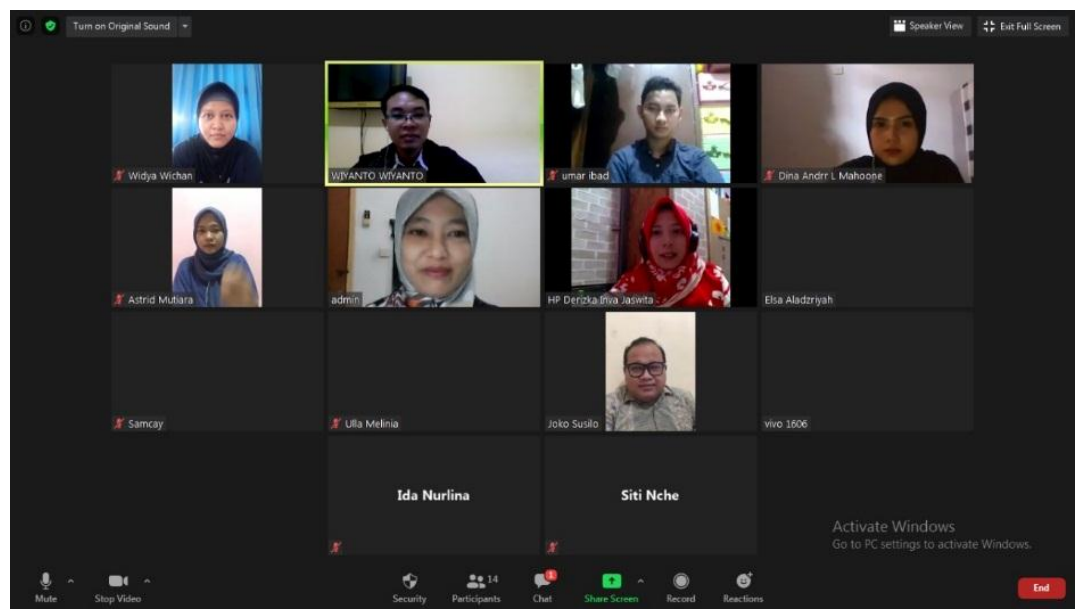

Gambar 2 Mentorship

\section{SIMPULAN}

Pelaksanaan kegiatan Pengabdian kepada Masyarakat yakni berupa Workshop dengan tema "Penguatan Usaha dengan Menggunakan Sistem Aplikasi By Data pada Usaha UKM Minuman Kekinian di Kota Tangerang Selatan"; yang dilaksanakan pada tanggal 31 Mei 2020 menggunakan aplikasi Zoom Meeting bertujuan untuk mengatasi permasalahan dalam mendapatkan ilmu pengetahuan secara teori dan praktek terkait dengan Inovasi Usaha berbasis sistem aplikasi. 
Setelah mengikuti kegiatan workshop ini dapat memicu motivasi para peserta dalam berwirausaha. Kelanjutannya adalah dengan menerapkan sistem aplikasi 'by data" dapat membantu para pelaku usaha minuman kekinian dalam mengembangkan usahanya sehingga tercapai peningkatan penjualan yang cukup signifikan dan memberi keuntungan secara ekonomis.

Tugas kami sebagai Tim Pengabdian kepada Masyarakat belumlah selesai sampai disini, kami berharap dapat menjaring lebih luas lagi mitra usaha yang bisa dijadikan mitra sharing session; sehingga harapan dan tujuan untuk menambah wawasan dan meningkatkan minat berwirausaha semakin luas menjangkau semua lapisan masyarakat. Selanjutnya juga menjalin kerjasama yang lebih luas lagi baik dengan mitra usaha lain maupun juga dengan pemegang kekuasaan (pemerintah) setempat dalam kegiatan mentoring yang dilakukan dalam rangka memberikan masukan dan pendampingan kepada masyarakat dalam menunjang kegiatan berwirausaha.

\section{DAFTAR PUSTAKA}

Ananda, A. D. \& Dwi Susilowati. (2017). Pengembangan Usaha Mikro Kecil Dan Menengah (Umkm) Berbasis Industri Kreatif Di Kota Malang. Jurnal Ilmu Ekonomi. 10 (10), 120-142.

Debbie, D., dkk. (2017). Aplikasi Pemesanan Makanan Dan Minuman Online Berbasis Mobile Browser Pada Restoran Tiga Saudara. Jurnal Inovasi Produk. 22(3)

Kotler, P., \& Gary Armstrong. (2012). Dasar-Dasar Pemasaran, Edisi kesembilan, Jilid 2, dialih bahasakan oleh Alexander Sindoro. Jakarta: Indeks

Kotler, P. (2015). Manajemen Pemasaran. Edisi 13. Jakarta: Erlangga

Mulyadi, W., dkk. (2016). Pengaruh Inovasi, Kreativitas, Dan Kepuasan Konsumen terhadap keunggulan kompetitif. Prosiding Seminar Nasional dan teknologi Informasi.

Sugiyono. (2008). Metode Penelitian Kuantitatif Kualitatif dan $R \&$ D. Bandung: Alfabeta. (2011). Metode Penelitian Kuantitatif Kualitatif dan R \& D. Bandung: Alfabeta. 